\title{
THE LESSER PESTILENCE: NON-EPIDEMIC PUERPERAL FEVER
}

\author{
by
}

\author{
STANLEY A. SELIGMAN *
}

Puerperal fever was first described by Hippocrates. ${ }^{1}$ However, the epidemic form of the disease does not seem to have existed before the mid-seventeenth century, when "an unknown affection occurred at Leipzig in 1652 and returned again in 1665. It attacked puerperal women and was so deadly that but one in ten escaped". ${ }^{2}$ Sporadic outbreaks were recorded over the following century ${ }^{3}$ until the winter of 1746 , when there was an epidemic at the Hôtel-Dieu in Paris. ${ }^{4}$ Thereafter the disease became increasingly prevalent; the first English epidemic was in 1760, at the British Lying-in Hospital. $^{5}$

Virulent epidemics continued together with sporadic cases until 1936 when, associated with the introduction of the sulphonamides, there was a sudden, profound and sustained fall in maternal mortality, which had remained static in England and Wales from the middle of the eighteenth century (when comprehensive reports on deaths in childbirth first became available). ${ }^{6}$ The experience of other countries was similar. $^{7}$

* Stanley A. Seligman, MD, FRCS, FRCOG, Luton and Dunstable Hospital, Dunstable Road, Luton, Beds. LU4 0DZ.

I wish to express my gratitude to Anne Cunnington and Drs A. G. and G. A. Pistofidis for invaluable help with translation of foreign papers. Irvine Loudon kindly advised on medical attitudes to the theory of endogenous infection in puerperal sepsis. My colleague at Luton, Trevor Willis, advised on all matters microbiological.

\footnotetext{
${ }^{1}$ Francis Adams, The genuine works of Hippocrates: translated from the Greek, vol. 1, London, The Sydenham Society, 1847, pp. 544-5.

2 Jean-Antoine-François Ozanam, Histoiremédicale, générale et particulière, des maladiesépidémiques, 2nd ed., Paris, 1835, p. 14. See also: James Hawley Burtenshaw, 'The fever of the puerperium (puerperal infection); a chronological review of the doctrines of its aetiology and of the methods of treatment from the earliest times to the present', N.Y. med. J. \& Phila. med. J., 1904, 79: 1073-8, 1134-8, 1189-94, 1234-8; 80: $20-5$.

${ }^{3}$ August Hirsch, Handbook of geographical and historical pathology, vol. 2, Chronic infective, toxic, parasitic, septic and constitutional diseases, London, New Sydenham Society, 1885, p. 422.

${ }^{4}$ Paul Jacques Malouin, 'Histoire des maladiesépidémiques de 1746, observées à Paris, en même temps que les différentes températures de l'air', Mém. Acad. roy. Sci., 1746, 160: 151-74. See also: Robert Lee, Researches on the pathology and treatment of some of the most important diseases of women, London, $\mathrm{S}$. Highley, 1833, pp. 5-8.

5 John Leake, Practical observations on the child-bed fever, London, Baldwin, 1772, p. 242.

${ }^{6}$ Irvine Loudon, 'Deaths in childbed from the eighteenth century to 1935', Med. Hist., 1986, 30: 1-41.

${ }^{7}$ Idem, 'Maternal mortality: 1880-1950. Some regional and international comparisons', Soc. Hist. Med., 1988, 1: 666-9.
} 


\section{Stanley A. Seligman}

Puerperal fever may be caused by different organisms; each produces its own characteristic picture. ${ }^{8}$ The common type, which can occur in epidemic or sporadic form, is due to the $\beta$-haemolytic streptococcus. Another common cause is the anaerobic organisms normally resident in the vaginas of healthy women, which only produce disease under certain conditions. A variety of other different organisms, less commonly, also give rise to infection.

It is the intention of this paper to explain why the type of fever due to the $\beta$-haemolytic streptococcus seems to have existed before the mid-seventeenth century in non-epidemic form only, and to trace the discovery of anaerobic infection as the other important cause of sporadic puerperal sepsis.

\section{SPORADIC AND EPIDEMIC PUERPERAL FEVER}

Evidence is lacking for the occurrence of epidemics of puerperal fever before the mid-seventeenth century. "With the eye of faith it is possible to perceive from early authors the existence of puerperal epidemics, but these ideas are too vague, and the relevant texts too obscure for any positive conclusion". 9 Thus an account of a supposed early epidemic from the pseudo-Hippocratic treatise De morbis mulierum was quoted by Hirsch, ${ }^{10}$ but he omitted that part of the text stating that puerperal women were not the only ones affected; in fact, fewer women than men were attacked. ${ }^{11}$

The onset and spread of epidemics of puerperal fever has been linked with the establishment of maternity hospitals and other institutions for the reception of the lying-in. ${ }^{12}$ This is manifestly not so. The first epidemic at the Hôtel-Dieu was in 1664, when a prodigious number of women died after their confinement; infection was attributed to impure air from a ward, filled with wounded, which was situated underneath the lying-in ward. ${ }^{13}$ This was a century and a half after the formation of the school of midwifery at the hospital, and there was no further outbreak until 1746. The British Lying-in Hospital had been open 11 years before its first outbreak in 1760, and other hospital beds for lying-in women had existed in London since 1747 without being affected. ${ }^{14}$

Why should a previously endemic condition assume epidemic proportions? It seems likely that this was due to a change in virulence of the $\beta$-haemolytic streptococcus responsible for the disease. It has been claimed, for example, that it was a sudden decrease in the virulence of the streptococcus in the mid 1930s, coinciding with the arrival of prontosil and sulphanilamide, which was the real cause of the fall in mortality associated with puerperal fever, and that the drugs did not really do what was claimed for them. Leonard Colebrook could find no such change at Queen Charlotte's Hospital, but wrote that on the other side of London, at Hampstead, the

${ }^{8}$ George F. Gibberd, 'Puerperal sepsis, 1930-1965', J. Obstet. Gynaec. Br. Commonw., 1966, 73: 1-10.

9 E. Hervieux, Maladies puerpérales, Paris, Adrien Delahaye, 1870, p. 3.

${ }^{10}$ Op. cit., note 3 above, p. 418.

${ }^{11}$ Adams, op. cit., note 1 above, p. 363.

12 Hirsch, op. cit., note 3 above, p. 419.

13 Philippe Peu, La pratique des accouchemens, Paris, Boudot, 1694, p. 268.

${ }^{14}$ Stanley A. Seligman, 'The Royal Maternity Charity: the first one hundred years', Med. Hist., 1980, 24: 403-18. 


\section{Non-epidemic puerperal fever}

puerperal fever cases in the LCC unit did appear to have been somewhat less severe in 1935 and the early part of 1936 than they had been before that time. ${ }^{15}$ Seventeenthand eighteenth-century accounts of puerperal fever and other diseases often caused by the $\beta$-haemolytic streptococcus-hospital gangrene, scarlet fever, and erysipelas-do indicate that there was an increase in the severity and contagiousness of such infections during these centuries.

Alexander Gordon, in his classic epidemiological study of an epidemic of puerperal fever in Aberdeen in 1789, stated:

The disease was new and unknown in Aberdeen ... The only disease supposed by the vulgar to be incident to lying-in women, is a disorder commonly called the weed, which is an ephemera similar to the paroxysm of an intermittent fever, and always terminates without any danger. ${ }^{16}$

"The weed"- a Scottish and Anglo-Irish term-was mainly applied in Scotland, although known in England. ${ }^{17}$ The condition, characterized by rigors, lasted between 18 and 36 hours and was not usually life-threatening.

Even after puerperal fever epidemics became established, not all of them were severe. There were no deaths associated with an outbreak in Derbyshire at a time when those in London were accompanied by many deaths. ${ }^{18}$

Hospital gangrene appears to have been a disease of all times and of every part of the habitable globe. ${ }^{19}$ However, since wounding of the skin predisposes to infection by a multitude of bacteria, there is no certainty that the streptococcus was responsible for many outbreaks.

The early history of scarlet fever is unclear since it was confused with measles and, as late as the seventeenth century, after it had been clearly described, was still regarded by many physicians as a modification of measles. ${ }^{20} \mathrm{~A}$ malignant as well as a mild form of the disease was first described by Richard Morton in 1694; and there is evidence that in the first half of the eighteenth century sore throats accompanied by scarlatiniform rashes were a serious medical problem. ${ }^{21}$

Erysipelas - an inflammatory reddening of the skin-was described mainly in association with wounds, in ancient and medieval times. ${ }^{22} \mathrm{~A}$ virulent form of epidemic erysipelas was first observed in 1750 at Caillan, on the bay of Saint-

\footnotetext{
${ }^{15}$ Leonard Colebrook, 'The story of puerperal fever-1800 to 1950 ', Br. med. J., 1956, i: 247-52.

${ }_{16}^{16}$ Alexander Gordon, A treatise on the epidemic puerperal fever of Aberdeen, London, Robinson, 1795, p. 4.

${ }_{17}$ Alexander Hamilton, $A$ treatise of midwifery, comprehending the whole management of female complaints, and the treatment of children in early infancy. To which are added prescriptions for women and children, $2 \mathrm{nd}$ ed., Edinburgh, Dickson, Creech \& Elliot, 1785, p. 253.

is William Butter, An account of puerperal fevers, as they appear in Derbyshire, and some of the counties adjacent, London, Payne, 1775, p. 121.

${ }_{19}$ Hirsch, op. cit., note 3 above, p. 476.

20 Idem, Handbook of geographical and historical pathology, vol. 1, Acute infectious diseases, London, New Sydenham Society, 1883, p. 171 .

${ }^{21}$ Charles Singer and E. Ashworth Underwood, $A$ short history of medicine, 2nd ed., Oxford, Clarendon Press, 1962, p. 203.

${ }_{22}$ Hirsch, op. cit., note 3 above, p. 390.
} 
Tropez. ${ }^{23}$ A similar type of malignant erysipelas swept the western hemisphere, starting in Nova Scotia in 1822 and growing into a pandemic which did not cease until the beginning of the $1860 \mathrm{~s}^{24}$

Laboratory studies have now confirmed that, not only do human historical, social, and economic factors cause variations in the frequency, severity and manifestations of infections due to group A streptococci, but also that these versatile microorganisms can undergo rapid change. ${ }^{25} \mathrm{~A}$ waxing and waning of the different organisms has been observed with isolates of one serotype predominating and then being replaced by another. ${ }^{26}$ There has been a recent relative increase in the number of strains of type 1 group A streptococci isolated in England, these being associated with invasive disease with a high fatality rate ${ }^{27}$ and there have been a number of maternal deaths reported from this form of infection. ${ }^{28}$

It seems likely that variations in the prevalence, toxicity, and infectivity of strains of the streptococcus were important factors in the establishment of an epidemic pattern of puerperal fever in the seventeenth and eighteenth centuries, and that these can explain the apparent absence of such a state before that time.

\section{MEDDLESOME MIDWIFERY}

For many centuries puerperal fever was attributed to retention of the menses, with such diverse precipitating factors as "catching cold, errors in diet, or anxiety of the mind" ${ }^{29}$ However, it was observed that retention of all or part of the afterbirth could lead to infection. In the seventeenth century, William Harvey commented on midwives being much to blame, "especially the younger and more meddlesome ones . . . by leaving behind portions of the membranes, or even the placenta itself", 30 whilst Mauriceau referred to their "rough handling". ${ }^{31} \mathrm{Peu}^{32}$ and Platter ${ }^{33}$ noted the effect of retention of the secundines, and Percival Willughby gave details of six cases

\footnotetext{
${ }^{23}$ M. Darluc, 'Des maladies épidémiques qui ont régné en 1750 \& 1751 à Caillan \& aux environs', in $M$. Vandermonde (ed.), Receuil périodique d'observations de médicine, chirurgie, pharmacie, \&c., vol. 7, Paris, Didot le jeune, 1757, p. 55.

${ }^{24}$ Hirsch, op. cit., note 3 above, pp. 396-405.

${ }^{25}$ Gene H. Stollerman, 'Changing group A Streptococci. The reappearance of streptococcal "toxic shock", Arch. intern. Med., 1988, 148: 1268-70.

${ }^{26}$ Ewa Gaworzewska and G. Colman, 'Changes in the pattern of infection caused by Streptococcus pyogenes', Epidem. Inf., 1988, 100: 257-69.

${ }^{27}$ G. Colman, A. Efstratiou, and E. T. Gaworzawska, 'The pyogenic streptococci', PHLS Microbiol. Dig., 1988, 5: 7-9. For recent American experience see: Dennis L. Stevens et al., 'Severe group A streptococcal infections associated with a toxic shock-like syndrome and scarlet fever toxin A', New Eng. J. Med., 1989, 321: 1-7. The original demonstration that different strains of haemolytic streptococci caused different clinical types of infection or could be harmless was given by Rebecca C. Lancefield and Ronald Hare in 'The serological differentiation of pathogenic and non-pathogenic strains of haemolytic streptococci from parturient women', J. experiment. Med., 1935, 61: 335-49.

${ }^{28}$ G. R. Swingler et al., 'Disseminated intravascular coagulation associated with group A streptococcal infection in pregnancy', Lancet, 1988, i: 1456-7.

29 John Leake, Practical observations on the child-bed fever, 3rd ed., London, Baldwin \& Evans, 1775, p. 41.

${ }^{30}$ William Harvey, Works. Translated, with a life of the author, by R. Willis, London, Sydenham Society, 1847 , p. 533.

${ }^{31}$ François Mauriceau, The diseases of women with child and in child-bed, tranl. Hugh Chamberlen, 3rd ed., London, Bell, 1697, pp. 271-2.

32 Op. cit., note 13 above, p. 1135.

${ }^{33}$ Felix Platter, De ventris dolore, Basel, 1656. See: Burtenshaw, op. cit., note 2 above, p. 1075.
} 
of puerperal sepsis, four of whom died, associated with retention of the placenta, trauma, or both. ${ }^{34}$ Other, eighteenth-century, authors recorded similar experiences. ${ }^{35}$

The importance of this type of fever following childbirth was put in perspective in 1861 by Semmelweis, who thought that such episodes could not be prevented and attributed them to self-infection.

The decomposed animal organic material which when absorbed brings on puerperal fever is rare in cases not conveyed to the individual from without but originates within the affected individual owing to the retention of organic material which should have been expelled in child-bed. Before its expulsion decomposition has already begun, and when absorption occurs puerperal fever is produced by Self-infection. These organic materials are the lochia, remnants of decidua, blood coagula which are retained within the cavity of the uterus. Or the decomposed animal organic material is the product of a pathological process, for example, the result of a forcible use of the midwifery forceps causing gangrene of bruised portions of the genital organs and consequent child-bed fever by Self-infection. ${ }^{36}$

As will be described presently, this type of infection is caused by the woman's own bacteriological flora, by anaerobic organisms normally present in the healthy vagina. "Self-infection" is an accurate description of the pathological process. It is ironic that the biographer of Semmelweis, having repeatedly emphasized how much of his work was not accepted because it was taken out of context, or misunderstood, rejected his observations on this type of sepsis as being founded on error. ${ }^{37}$

\section{THE ACCEPTANCE OF ANAEROBES AS A CAUSE OF DISEASE}

Modern views on the nature of surgical sepsis started with the work of Robert Koch in the 1870s, work that was continued by Alexander Ogston, assistant surgeon to the Aberdeen Royal Infirmary. ${ }^{38}$ Ogston not only distinguished streptococci, which he named, from staphylococci, but also demonstrated that the micrococci that he isolated from abscesses were anaerobic organisms. To understand the difficulties associated with the investigation of the role of anaerobic organisms in the production of infection it is necessary to appreciate concepts of bacteria as a cause of disease

\footnotetext{
${ }^{34}$ Percival Willughby, Observations in midwifery, edited from the original MS by Henry Blenkinsop, 1863, with a new introduction by John L. Thornton, Wakefield, SR Publishers Ltd., 1972, pp. 40, 88, 94, $117,171,218,222$.

35 Guillaume Mauquest de La Motte, A general treatise of midwifery: illustrated with upwards of four hundred curious observations and reflections concerning that art... Translated into English by Thomas Tomkyns, London, Waugh, 1746, p. 488; Benjamin Pugh, A treatise of midwifery, chiefly with regard to the operation. With several improvements in that art, London, Buckland, 1754, pp. 25, 31; Thomas Kirkland, $A$ treatise on child-bed fevers, and on the methods of preventing them. Being a supplement to the books lately written on the subject, London, Baldwin \& Dawson, 1767, pp. 64-6; John Clarke, Practical essays on the mangement of pregnancy and labour; and on the inflammatory and febrile diseases of lying-in women, London, Johnson, 1793, p. 98.

${ }^{36}$ Ignaz Philipp Semmelweis, Die Aetiologie, der Begriff und die Prophylaxis des Kindbettfiebers, Pest, Vienna and Leipzig, C. A. Hartleben, 1861. Translated in, Sir William J. Sinclair, Semmelweis: his life and doctrine, Manchester University Press, 1909, p. 205.

${ }^{37}$ Ibid., pp. 208, 367.

${ }^{38}$ Leonard G. Wilson,'The early recognition of streptococci as causes of disease', Med. Hist., 1987, 31: 403-14.
} 
before the present century. Initially, it was not even agreed whether bacteria were the cause or the product of disease.

In 1680 , in his $32^{\text {nd }}$ letter to the Royal Society, Anton van Leeuwenhoek described how animacules had developed in a sealed glass tube containing powdered pepper, clear rain water, and a minimal amount of air. Nearly 100 years later Lazzaro Spallanzani, the Italian naturalist who destroyed the doctrine of spontaneous generation, showed that animacules could develop in a high vacuum and live and move for 16 days. ${ }^{39}$ These observations were overlooked until the second half of the nineteenth century, when Louis Pasteur undertook his investigations into the manufacture of alcohol from beet. In one experiment he put a drop of fermenting fluid on a slide under a cover slip. On looking down the microscope he saw that, whilst the organisms in the centre of the field were moving actively, the ones at the edge near to the air became sluggish; they seemed to want to move to the centre away from the free oxygen. Pasteur called these organisms anaérobies, as distinct from aérobies. ${ }^{40}$

It was at first believed that every bacterial species appeared in several morphological and physiological forms which could be changed, the one into the other, by external conditions, this process being called "adaption". The term "pleomorphism" was introduced to describe the supposed change of bacteria from spherical cocci to bacillary rods to spirals. Although bacteriology began to emerge as a definite science towards the end of the 1870s, the doctrine of pleomorphism lingered, with the result that many workers investigating the microbiology of infection were unaware that they were dealing with mixed cultures rather than a single specific agent, particularly where anaerobic agents were involved. From her investigation of war wounds in Flanders, Muriel Robinson concluded that mixed cultures accounted for most of the anomalies. ${ }^{41}$ This and similar findings by others were largely ignored and it was only in the 1980s that the importance of mixed microbial populations in infection became generally understood. ${ }^{42}$

A further obstacle to the investigation of anaerobic infection was the difficulty of isolating the organisms. It was not until 1916, when MacIntosh and Fildes published their first paper on the anaerobic jar, that plate cultures could be made easily and consistently. ${ }^{43} \mathrm{~A}$ do-it-yourself approach was prevalent in laboratory practice at that time and the authors suggested the use of a paint tin with a lever-off lid.

Despite all these difficulties the importance of anaerobic infection in non-epidemic puerperal fever had already been established by French and German workers, although it was to be some time before their results were to be rediscovered and accepted in America and England.

\footnotetext{
${ }^{39}$ William Bulloch, The history of bacteriology, London, Oxford University Press, 1938 (repr. 1960), p. 232.

40 Ibid., p. 232.

41 Muriel Robertson, 'Notes upon certain anaerobes isolated from wounds', J. Path. Bact., 1915-6, 20: 327-49.

42 B. Styrt and S. L. Gorbach, 'Recent developments in the understanding of the pathogenesis and treatment of anaerobic infections', N. Eng. J. Med., 1989, 321: 240-6, 298-302.

43 James McIntosh and Paul Fildes, 'A new apparatus for the isolation and cultivation of anaerobic micro-organisms', Lancet, 1916, i: 768-70.
} 


\section{Non-epidemic puerperal fever}

\section{ANAEROBIC INFECTION AS A CAUSE OF PUERPERAL FEVER}

The first to isolate an anaerobe from a case of puerperal fever was E. Levy, clinical assistant to the Department of Surgery in the University of Strassburg.

Frau F. . . following a normal birth in June 1890 developed severe right iliac fossa pain on the third day. Soon after, a large swelling followed, which affected the hip joint ... The pain got worse so that the patient was confined to bed for five months. She was admitted to hospital at the end of November $1890 \ldots$. The whole of the upper third of the right thigh was very swollen and fluctuant ... On deep palpation one clearly has a feeling as if pressing a cavity filled with air. Percussion over the abscess produces a light tympanic sound ... With a little firm pressure one can bring the deep masses above and below Poupart's ligament towards each other as proof that one is dealing with a single large abscess ...

On 30 November 1890 , operation under chloroform anaesthetic ... To collect the gas, puncture of the abscess is made on the outside of the thigh near to the trochanter with a boiled trocar. Gas streams out at once ... the abscess in incised and some of the foul smelling pus taken for bacteriological examination ...

After the operation the fever fell at once. On the first change of dressing there was only minimal discharge. After eight days a drain could no longer be introduced and after three weeks the woman was discharged completely cured of her large pelvifemoral abscess. ${ }^{44}$

Professor Hoppe-Seyler's chemical analysis of the gas showed, by volume, carbon dioxide, 47.845\%; hydrogen, 20.134\%; nitrogen, $32.021 \%$.

Levy correctly anticipated the presence of a polymicrobial infection, including anaerobes, and so did not use bouillon for culture as advocated by the Paris school, as this would not separate out the different organisms. He used gelatin plates and agar tubes incubated anaerobically. The gelatin plates grew only a few colonies of Streptococcus pyogenes. These grew also in the agar tubes in small amounts, but the main colonies, resembling the anthrax bacillus, displayed a fine granular structure surrounded by a tangle of fine, entwined threads. Around each colony a vacuole of gas had formed. Microscopically, the colonies consisted of quite short fine immobile bacteria arranged in long chains and threads of up to 30 or more segments. They stained Gram-positive. Whilst it is impossible to identify this organism with certainty, it was most probably a Clostridium, possibly $C$. sporogenes or $C$. sordellii.

The clinical description of the patient's condition is typical of anaerobic pelvic infection, with a chronic course and the presence of profuse stinking pus.

In 1893, M. A. Veillon reported the recovery of an anaerobe from pus from a Bartholin's abscess and described how this organism, either alone or with other bacteria, could produce fetid suppuration. ${ }^{45} \mathrm{He}$ thought that this Micrococcus fetidus was probably the same as that isolated from dental caries by Rosenbach in 1884 . Under Veillon's direction at the Faculty of Medicine in Paris, anaerobic infection in

\footnotetext{
${ }^{44}$ E. Levy, 'Ueber einen Fall von Gasabscess', Dt. Z. Chir., 1891, 32: 248-51.

${ }^{45}$ M. A. Veillon, 'Sur un microcoque anaérobie trouvé dans suppurations fétides', C. Mém. Soc. biol., 1893, 5: 807-9.
} 
man was extensively investigated, including female genital $\operatorname{tract}^{46}$ and putrid puerperal infections. ${ }^{47}$

In Germany, the microbiology of the female genital tract was further studied by Bernhard Krönig. He had learned the fundamentals of bacteriology from Robert Koch in Berlin. Later, accompanied by his friend and co-worker Carl Menge, he moved to Leipzig as assistant to Paul Zweifel. In his post-doctoral lecture of 1895 , Krönig described fever following childbirth as a polymicrobial infection essentially determined by the anaerobes, ${ }^{48}$ but German workers were divided in their views as to whether anaerobic organisms could cause disease or were merely commensal. It was Hugo Schottmüller (1867-1936) who finally was able to isolate and culture these organisms before and after death in severe cases of puerperal sepsis.

Schottmüller became director of the Medical Polyclinic in Hamburg-Eppendorf. He was a clinical bacteriologist and introduced a number of techniques still in use today, including blood-culture and the blood-agar plate. He seems to have been unaware of much of the research into anaerobic infection being carried out in Paris.

From 1903 Schottmüller was able to culture anaerobes from blood by incubating it in bouillon. Anaerobic conditions occurred from the blood clotting or settling to the bottom of the tubes. Growth was demonstrable after 24 hours. He also successfully used stab cultures in agar to which he had added a reducing substance.

On 16 November 1909, Schottmüller spoke to the Biological Association of Hamburg on the importance of some of the anaerobic bacteria in medicine, most specifically in puerperal infections. He used the term "puerperal" to mean following pregnancy, rather than following the birth of a child (L. puer-child; parere-to bring forth) and all his "puerperal" infections were in fact post-abortal infections. Infection following abortion, invariably due to interference with the pregnancy, differs from infection following childbirth. He presented case histories of 16 post-abortal infections as well as nine others with pelvic inflammatory disease, otitis media, lung abscess, pulmonary tuberculosis, and urinary tract infection. Although he included patients infected with tetanus (Clostridium tetani) and gas gangrene (C. perfringens) organisms, those described were mainly due to anaerobic cocci, which he called Streptococcus putridus from the offensive smell. He showed clearly the tendency for these infections to invade the blood stream, with the production of rigors, and proceed to venous thrombosis, which could give rise to septic embolism. The common findings at post-mortem were septic endometritis, septic thrombophlebitis of the pelvic and hypogastric veins, lung abscesses, and splenomegaly. He concluded: "We now know the reason for puerperal sepsis. The only thing that remains is to find the appropriate treatment." By the time the report of the meeting was published, he was

\footnotetext{
46 J. Hallé, Recherches sur la bactériologie du canal génital de la femme (état normal et pathologique). Thesis, Faculty of Medicine, University of Paris, 1898.

${ }^{47} \mathrm{C}$. Jeannin, Etiologie et pathogénie des infections puerpérales putrides (recherches cliniques et bactériologiques). Thesis, University of Paris, 1899.

${ }^{48}$ H. Spitzbart, 'Zur Geschichte der Anaerobier in der Geburtshilfe', Zent bl. Gynäk., 1986, 108: 1261-3.
} 


\section{Non-epidemic puerperal fever}

able to add details of six cases which followed childbirth as distinct from abortion: five from $S$. putridus and one from $C$. perfringens. ${ }^{49}$

A year after this initial paper, Schottmüller published two more articles, on the aetiology of puerperal fever ${ }^{50}$ and on bacteriological investigations and methods therein. ${ }^{51}$ In a series of 50 cases of true post-partum infection he found anaerobic infections to be as common as those due to aerobic streptococci. Most of his positive cultures were from the cervix, although he was able to isolate the same organism from the blood on a number of occasions. He noted that an anaerobic infection could be suspected if there was an offensive-smelling vaginal discharge which differed from that produced by infections with other bacteria. He described how anaerobic infections often gave rise to salpingitis and pelvic abscess formation; venous thrombosis was another common complication. ${ }^{52} \mathrm{He}$ thought that anaerobic infections usually were caused by the passage of the streptococcus, which was commensal in the vagina, into the uterus from intrauterine intervention or operation. $\mathrm{He}$ also thought that the infections had a pronounced contagious property with an increase in virulence through transmission from person to person or when the organism entered the blood stream. He was undoubtedly wrong about the infectivity and change in virulence of the normal resident flora, but all of his other findings have since been confirmed. He also had more severe infections and deaths in those infections due to anaerobic streptococci, but this may have been associated with the factors leading to the superadded infection.

By 1923 Schottmüller had collected 231 fatal cases following labour, with anaerobic streptococci isolated from 72, seven of these being polymicrobial. In 41 of the anaerobic infections, death was from peritonitis. ${ }^{53}$ Despite all this he seemed optimistic that the problem of puerperal sepsis would be overcome and that, although it would not disappear altogether, the number of deaths in childbirth could be reduced from its still frightening height to a minimal figure. ${ }^{54}$ Schottmüller died in 1936, the year when sulphonamides were coming into use and turning his hope into reality.

In America the role of anaerobic streptococci in puerperal infection was investigated by Otto Schwarz and William J. Dieckmann at Washington University School of Medicine. Schottmüller's work was mentioned in at least two of the then-current American textbooks of obstetrics, but it was thought that, although anaerobic streptococci were occasionally found in puerperal infections, Schottmüller

\footnotetext{
${ }^{49}$ Hugo Schottmüller, 'Zur Bedeutung einiger Anaëroben in der Pathologie, insbesondere bei puerperalen Erkrankungen (Streptococcus putridus, Bac. phlegm. emphysemat., Bac. tetani.)', Mitt. Med. Chir., 1910, 21: 450-90.

50 Idem, 'Aetiologie des febris puerperalis und febris in puerperio', Münch. med. Wschr., 1911, 58: 557-8.

51 Idem, 'Ueber bakteriologische Untersuchungen und ihre Methoden bei febris puerperalis', ibid., pp. 787-9.

52 This work was undertaken in Schottmüller's department by Konrad Bingold; 'Putride embolische Lungeninfektionen und Pathologie', Virchow's Arch., 1921, 232: 22-34.

${ }^{53}$ Hugo Schottmüller, Leitfaden für die klinisch-bakteriologischen Kulturmethoden, Berlin, Urban \& Schwarzenberg, 1923.

${ }^{54}$ Idem, 'Die puerperale Sepsis', Münch. med. Wschr., 1928, 75: 1580-3, 1634-8.
} 
overestimated the frequency of this type of infection. ${ }^{55}$ The interest of Schwarz and Dieckmann was stimulated by the repeated negative cultures they obtained in cases that they thought were obviously infected clinically.

In July 1924 the School's Department of Obstetrics took over its own bacteriology work, after which all the uterine and blood cultures were grown both aerobically and anaerobically. It was at this time that Schwarz and Dieckmann became interested in Schottmüller's researches. They could find only one report of serious puerperal infection due to anaerobic streptococci in the American literature, from 1905. They also found a report of the accidental culture of an anaerobic streptococcus in the blood following a death from puerperal infection reported from the Rotunda Hospital, Dublin in 1925.

Schwarz and Dieckmann presented their findings at a meeting of the Section of Obstetrics of the Southern Medical Association in Dallas, Texas, in $1925 .^{56}$ They were able to demonstrate that Schottmüller was right about the relative incidence of the various types of puerperal infection, and that their experience confirmed the clinical characteristics of the cases that he had described. Anaerobic streptococci played a considerable role as a causative factor.

Between July 1924 and September 1926 they had a total of 45 puerperal infections with 10 deaths from 1,913 deliveries. ${ }^{57}$ Anaerobes were present in eight of the deaths, three of which were associated with thrombophlebitis. They thought that the relatively small number of patients developing thrombophlebitis was due to prompt treatment of the uterine lesion. In any case where there was a profuse foul-smelling discharge they made a point, when they took their uterine culture, of removing retained products or clots digitally or with a blunt curette followed by a 1:4,000 potassium permanganate douche. In cases of thrombophlebitis they had hoped, on account of the saprophytic character of the organism in the non-invasive state, that its virulence might become exhausted; and that by supporting the patient with blood transfusions of $500 \mathrm{ml}$ or more, given early and repeated frequently, and keeping up her nutrition with forced feeding, the patient's life might be saved; but of four cases handled in this manner, only one recovered. They thought, from a review of the literature, that in future cases of pelvic thrombophlebitis due to anaerobic organisms they would attempt ligation of all of the pelvic veins, even though the results in Schottmüller's clinic had not been gratifying. Other modes of treatment which they used were intravenous analine dyes (mercurochrome and gentian violet), neoarsphenamine, autogenous vaccine, and anti-streptococcal serum.

A later paper from Washington gave extended experience to 1930, with a further 11 deaths from puerperal sepsis. ${ }^{58}$ The conclusion was that anaerobic streptococcal infections would perhaps best be reduced by using some antiseptic preparation in the

\footnotetext{
${ }^{55}$ In a series of 150 cases, described in 1903, in which the temperature rose to $101^{\circ} \mathrm{F}$ or higher during the first 10 days of the puerperium, unidentified anaerobic bacteria were demonstrated in eight. J. Whitridge Williams, Obstetrics, New York and London, D. Appleton, 1903, p. 762.

${ }^{56}$ Otto Schwarz and William J. Dieckmann, 'Anaerobic streptococci: their role in puerperal infection', South. med. J., 1926, 19: 470-9.

${ }_{57}$ Ibidem, 'Puerperal infection due to anaerobic streptococci', Am. J. Obstet. Gynec., 1927, 13: 467-85.

${ }^{58}$ T. K. Brown, 'The incidence of puerperal infection due to anaerobic streptococci', ibid., 1930, 20: 300-9.
} 


\section{Non-epidemic puerperal fever}

vagina at the beginning of and during labour, although no particular agent could be recommended, ${ }^{59}$ and that the subject would command one of the most important investigations in modern obstetrics.

Other American workers, namely John Harris and Howard Brown, from the Johns Hopkins Hospital, also investigated the bacteriology of the genital tract in pregnancy. ${ }^{60}$ They collected 113 cases of streptococcal puerperal infection with approximately equal numbers of aerobic and anaerobic organisms, and emphasized the necessity of using anaerobic methods in suspected cases of such infection.

By this time the place of anaerobic infection in puerperal sepsis was being investigated in England, although initially this was in complete ignorance of the work already carried out in Germany and America. The researcher concerned was Leonard Colebrook, bacteriologist to Queen Charlotte's Hospital, London. ${ }^{61}$

Between 1923 and 1928 Colebrook investigated about 230 cases of severe and moderately severe puerperal fever. He isolated pyogenic streptococci from the blood or uterus in about two-thirds of them but was puzzled by cases that he encountered from time to time in which, in spite of frequent rigors and high pyrexia, the blood cultures were always negative. One such patient in 1928 had several weeks of irregular fever with almost daily rigors, but repeatedly negative blood cultures. Finally, by using a strictly anaerobic technique, he succeeded in isolating a gas-forming streptococcus which could not be subcultured aerobically. The woman eventually developed a large abscess with foul-smelling pus, from which he isolated the same organism.

From his experience with this patient Colebrook determined to investigate future cases of puerperal fever more carefully, with a view to detecting these infections if they should occur, and he made anaerobic cultures from the cervix of every case, modifying the routine procedure for blood cultures to favour the growth of strict anaerobes as well as aerobic organisms. He realized that uterine cultures might not give a reliable picture of the bacteria causing the sepsis, but accepted the evidence from blood cultures as indicating true infection.

From October 1928 until June 1930 he was able to investigate 76 cases of puerperal fever, as a result of which he had to change many of his beliefs about the nature of the infection. He reported a negative blood culture in 44 cases and positive in $34 .{ }^{62}$ There was a pure growth of a haemolytic streptococcus in 12 with anaerobic cocci in 17 , the remaining five positive cultures being different organisms. Of the positive anaerobic cultures, nine gave a pure culture of a single type of streptococcus, the other eight being polymicrobial. Most of the patients developing anaerobic infections had been subjected to some type of intrauterine manipulation, the commonest being manual removal of the placenta. In no case was the infection fulminating. The women were much less ill and the fever less sustained than in women infected with haemolytic

\footnotetext{
${ }^{59}$ As early as 1896, Charles Jewett had concluded that prophylactic vaginal douching as a routine measure was unnecessary, and even in skilled hands was probably injurious: 'The question of puerperal self-infection', Am. gynaec. obstet. J., 1896, 8: 417-29.

$60 \mathrm{John} \mathrm{W.} \mathrm{Harris} \mathrm{and} \mathrm{J.} \mathrm{Howard} \mathrm{Brown,} \mathrm{'A} \mathrm{clinical} \mathrm{and} \mathrm{bacteriological} \mathrm{study} \mathrm{of} 113$ cases of streptococcal puerperal infection', Bull. Johns Hopkins Hosp., 1929, 44: 1-31.

${ }^{61}$ Leonard Colebrook, 'Infection by anaerobic streptococci in puerperal fever', Lancet, 1930, ii: 134-7.

62 The figures in the original text do not add up to a correct total.
} 
streptococci. They had frequent rigors but their general condition remained good with a slow pulse. When the infection was prolonged severe anaemia developed. Septic thrombus formation was frequent, often giving rise to abscesses from embolism by infected clot.

In September 1930 an isolation block was opened at Queen Charlotte's Hospital for the reception and treatment of cases of puerperal sepsis and five months later the accompanying laboratory began providing a full service. Leonard Colebrook realized that Queen Charlotte's Hospital, still situated in Marylebone at that time, was never likely to provide enough patients to make any study worthwhile. Accordingly, the co-operation was sought of the London County Council and of numerous County, Borough, District, and Town Councils in south-east England and even further afield, as well as general practitioners. All were asked if they would be prepared to send their patients to the Isolation Block to provide ample material for study. ${ }^{63}$ Working with R. M. Fry, R. Hare, and Elizabeth Cooper, Colebrook was able to confirm his earlier impression, that infections by anaerobic streptococci were particularly prone to follow upon internal manipulations and exhausting labour. ${ }^{64}$ Over the next three years more than 500 cases were admitted to the block, 60 per cent of them from outside the hospital. ${ }^{65}$ Of in-patients transferred to the isolation block only 25 per cent were found to be infected with haemolytic streptococci, whilst over half of the district cases were so affected, an observation not in accord with the then-accepted view that the incidence of potentially serious infection was greater among women delivered in hospital than among those delivered in their own homes. It was established beyond doubt that anaerobic cocci were potentially pathogenic organisms.

The most constant pathological condition associated with anaerobic septicaemia was shown to be thrombophlebitis spreading upwards from the pelvic veins. ${ }^{66}$ The cases were sporadic, with nothing to suggest epidemic spread.

With this work, the clinical picture of puerperal infection by non-sporing anaerobes normally resident in the woman's own genital tract became complete. The "selfinfection" theory of Semmelweis was confirmed, together with the relationship of this type of infection to traumatic delivery and retained products. The question of whether healthy or diseased vaginal secretions could infect the woman had finally been answered. ${ }^{67}$ The association between endogenous infection and obstetric intervention in labour also destroyed the view, popular with many doctors, that it was the woman who was to blame for infecting herself, rather than her medical attendants.

${ }^{63}$ Sir John Dewhurst, Queen Charlotte's. The story of a hospital, Privately printed, 1989, p. 187. It appears that some of the cases admitted were post-abortal rather than puerperal; a book of records of some of the early cases treated with sulphonamides, in the library of the Royal College of Obstetricians and Gynaecologists, includes one case following abortion out of a total of 23 .

${ }_{64}$ Leonard Colebrook, 'Infection by anaerobic streptococci in puerperal fever', Br. med. J., 1931, ii: 777.

${ }^{65}$ L. C. Rivett, Leslie Williams, Leonard Colebrook, and R. M. Fry, 'Puerperal fever-a report upon 533 cases received at the isolation block of Queen Charlotte's Hospital', Proc. Roy. Soc. Med., 1933, 26: 1161-75.

${ }^{66}$ It was R. M. Fry, working in Leonard Colebrook's laboratories in the 1930s, who showed that each of the more common pyogenic organisms tended to produce its own characteristic pathological lesions.

67 Jewett, op. cit., note 59 above, p. 418. 
There remained one area in which the work done up to that time was incompletefull knowledge of the organisms involved. This had to await improvements in the technical methods of culturing, isolating, and identifying non-sporing anaerobic bacteria. $^{68}$

One feature of the septicaemic cases at Queen Charlotte's Hospital was that more than half of them yielded two or more bacterial types on blood culture. Leonard Colebrook, together with Ronald Hare, was able to detect four types, although they thought that one of them might have been a variant of one of the others. Anothertype C-produced coal-black colonies on culture. ${ }^{69}$ Schwarz and Dieckmann had frequently encountered a similar organism in their researches. ${ }^{70}$ They called it an anaerobic streptococcus, and described it as a Gram negative cocco-bacillus which produced a black pigment, probably melamine, on blood agar and had haemolytic properties. There seems little doubt that these organisms were not cocci but pigmented Bacteroides, now known to be a common infecting agent in pelvic sepsis.

The importance of Bacteroides in anaerobic infection was slow to gain recognition. The genus was named in $1919,{ }^{71}$ and isolated and described in $1921 .^{72}$ The first review of Bacteroides bacteraemia was not published until 1932; the authors could find references to only ten cases in the literature and added two of their own. Only one case, from 1927, was from a puerperal pelvic infection. ${ }^{73}$ As late as 1967 Ronald Hare, Colebrook's co-worker and a recognized authority on anaerobic infection, reviewing recent advances, merely mentioned the suggestion by Dr Hildred Baker that synergism with anaerobic Gram negative bacilli, which were frequently present with anaerobic cocci, might be an important factor in the causation of puerperal fever. $^{74}$

Another non-sporing anaerobe which could cause puerperal infection was described by Harris and Brown from the Johns Hopkins Hospital in $1927 .{ }^{75}$ They named it Actinomyces pseudonecrophorus. In modern terminology, this is a fusobacterium-F. necrophorum.

\section{PUERPERAL FEVER TODAY}

Fatal puerperal sepsis is rarely seen nowadays in the developed world although, as discussed above, there has been a worrying resurgence of the more toxic species of the

\footnotetext{
${ }^{68}$ L. V. Holdeman and W. E. C. Moore, Anaerobic laboratory manual, Blacksburg, The Virginia Polytechnic Institute Anaerobe Laboratory and State University Anaerobe Laboratory, 1972.

${ }^{69}$ Leonard Colebrook and Ronald Hare, 'The anaerobic streptococci associated with puerperal fever', J. Obstet. Gynaec. Br. Emp., 1933, 40: 609-29.

${ }^{70} \mathrm{Op}$. cit., note 57 above, p. 471.

${ }^{71}$ A. Castellani and A. J. Chalmers, Manual of tropical medicine, London, Baillière Tindall, 1919, pp. 933, 937.

72 Wade W. Oliver and William B. Wherry, 'Notes on some bacterial parasites of the human mucous membranes', J. infect. Dis., 1921, 28: 341-4.

${ }^{73}$ Luther Thompson and Donald C. Beaver, 'Bacteremia due to anaerobic gram-negative organisms of the genus Bacteroides', Med. Clinics N. Am., 1932, 15: 1611-26.

${ }^{74}$ Ronald Hare, 'The anaerobic cocci', in A. P. Waterson (ed.), Recent advances in medical microbiology, London, J. \& A. Churchill, 1967, p. 306.

$75 \mathrm{John}$ W. Harris and J. Howard Brown, 'Description of a new organism that may be a factor in the causation of puerperal infection', Bull. Johns Hopkins Hosp., 1927, 40: 203-15.
} 


\section{Stanley A. Seligman}

group A $\beta$-haemolytic streptococcus formerly associated with fever epidemics. When it occurs, sepsis is generally due to organisms different from those commonly implicated in the days before the introduction of sulphonamides and such later antimicrobial drugs as metronidazole, effective in the prevention as well as the cure of anaerobic infections. In England and Wales during the years 1982-4, the last period for which we have full information, there was not a single death from puerperal infection. ${ }^{76}$

Sepsis following delivery is still a cause for concern, particularly after Caesarean section, with febrile morbidity in 44 per cent, ${ }^{77}$ and wound infection in up to 14 per cent of women. ${ }^{78}$ Interest in the harmful effects of anaerobic infection on childbearing has largely switched to the time before delivery, when the presence of anaerobes in the vagina is associated with premature rupture of the membranes, pre-term labour, and amniotic fluid infection. ${ }^{79}$

In the developing world, post-partum infection remains a serious problem, and the availability of a large array of recent and potent antibiotics has not helped to diminish deaths from this cause. ${ }^{80}$

\footnotetext{
${ }^{76}$ Sir Alexander Turnbull et al., Report on confidential enquiries into maternal deaths in England and Wales 1982-1984, London, HMSO, 1989, p. 56.

${ }_{77}$ H. A. Hirsch, 'Prophylactic antibiotics in obstetrics and gynecology', Am. J. Med., 1985, 78 (suppl. 6B): 170-6.

18 B. R. Moir-Bussy, R. M. Hutton, and J. R. Thompson, 'Wound infection after Caesarean section', J. hosp. Infect., 1984, 5: 359-70.

${ }^{79}$ M. G. Gravitt et al., 'Independent associations of bacterial vaginosis and Chlamydia trachomatis infection with pregnancy outcome', J. Am. med. Ass., 1986, 256: 1899-1903.

80 A. A. El Kady et al., 'Obstetric deaths in Menoufia Governorate, Egypt', Br. J. Obstet. Gynaec., 1989, 96: 9-14.
} 